Pesq. Vet. Bras. 29(5):435-438, maio 2009

\title{
Lesões de pele causadas pelos espinhos de Mimosa pudica (Leg. Mimosoideae) nos membros de bovinos e ovinos no estado do Pará 1
}

\author{
José Diomedes Barbosa ${ }^{2 *}$, José Alcides Sarmento da Silveira ${ }^{2}$, Tatiane Teles \\ Albernaz ${ }^{2}$, Natália da Silva e Silva², Alessandra dos Santos Belo Reis ${ }^{2}$, Carlos \\ Magno Chaves Oliveira², Gabriela Riet-Correa² e Marcos Dutra Duarte ${ }^{2}$
}

\begin{abstract}
Barbosa J.D., Silveira J.A.S, Albernaz T.T., Silva N.S., Belo Reis A.S., Oliveira C.M.C., Riet- Correa G. \& Duarte M.D. 2009. [Cutaneous lesions of the legs caused by the thorns of Mimosa pudica (Leg. Mimosoideae) in cattle and sheep in the State of Pará.] Lesões de pele causadas por Mimosa pudica (Leg. Mimosoideae) nos membros de bovinos e ovinos no Estado do Pará. Pesquisa Veterinária Brasileira 29(5):435-438. Central de Diagnóstico Veterinário, Faculdade de Medicina Veterinária, Universidade Federal do Pará, Campus Castanhal, Rua Maximino Porpino da Silva 1000, Castanhal, PA 68740-080, Brazil. E-mail: diomedes@ufpa.br

A condition of cattle and sheep characterized by ulcerous and granulomatous skin lesions of the legs was studied. Epidemiological data and the nature of the lesions indicate that they are caused by the thorns of Mimosa pudica (Leg. Mimosoideae). The disease was observed only in pastures largely infested by the plant, and animals recover quickly when moved from them.
\end{abstract}

INDEX TERMS: Cutaneous lesions, skin, cattle, sheep, Mimosa pudica, Leguminosae Mimosoideae, traumatic lesions.

RESUMO.- Foi estudada uma doença em bovinos e ovinos caracterizada por lesões ulcerativas e granulomatosas da pele dos membros. Os estudos epidemiológicos e patológicos permitiram concluir que essas lesões são causadas pelos espinhos de Mimosa pudica (Leg. Mimosoideae). A doença foi observada somente em pastagens acentuadamente infestadas e os animais se recuperaram rapidamente após retirados destes pastos. Nos ovinos as lesões atingiam partes mais altas dos membros do que nos bovinos, devido ao seu menor porte.

TERMOS DE INDEXAÇÃO: Lesões de pele, bovinos, ovinos, Mimosa pudica, Leguminosae Mimosoideae, malícia, lesões traumáticas.

\footnotetext{
${ }^{1}$ Recebido em 17 de dezembro de 2008.

Aceito para publicação em 24 de janeiro de 2009.

Este trabalho recebeu apoio do Programa Instituto do Milênio (Proc.420012/2005-2).

${ }^{2}$ Central de Diagnóstico Veterinário da Faculdade de Medicina Veterinária, Universidade Federal do Pará, Campus Castanhal, Rua Maximino Porpino da Silva, 1000, Centro, Castanhal, PA 68740-080, Brasil. *Autor para correspondência: diomedes@ufpa.br
}

\section{INTRODUÇÃO}

Em diversas fazendas, localizadas no Estado do Pará, observam-se lesões na pele dos membros de bovinos e ovinos, de etiologia desconhecida. De acordo com os históricos, os animais afetados pastam em piquetes com grande quantidade de uma planta conhecida popularmente como "malícia", "dormideira", "sensitiva", "arranhadeira", "não-me-toque" e "dorme-maria". Em função disso, o presente trabalho teve como objetivo estudar a natureza dessas feridas e estabelecer a sua etiologia.

\section{MATERIAL E MÉTODOS}

Os dados epidemiológicos e clínico-patológicos foram obtidos em visitas a duas propriedades localizadas no município de Castanhal, Pará. Foram examinados 40 bovinos com 4-8 meses e 50 ovinos, com 2-4 anos de idade. No exame clínico, verificaram-se a localização, a natureza e a intensidade das lesões. Também, realizou-se biopsia da pele afetada de quatro bovinos. O material foi fixado em formol a $10 \%$ e processado rotineiramente para exame histopatológico. 


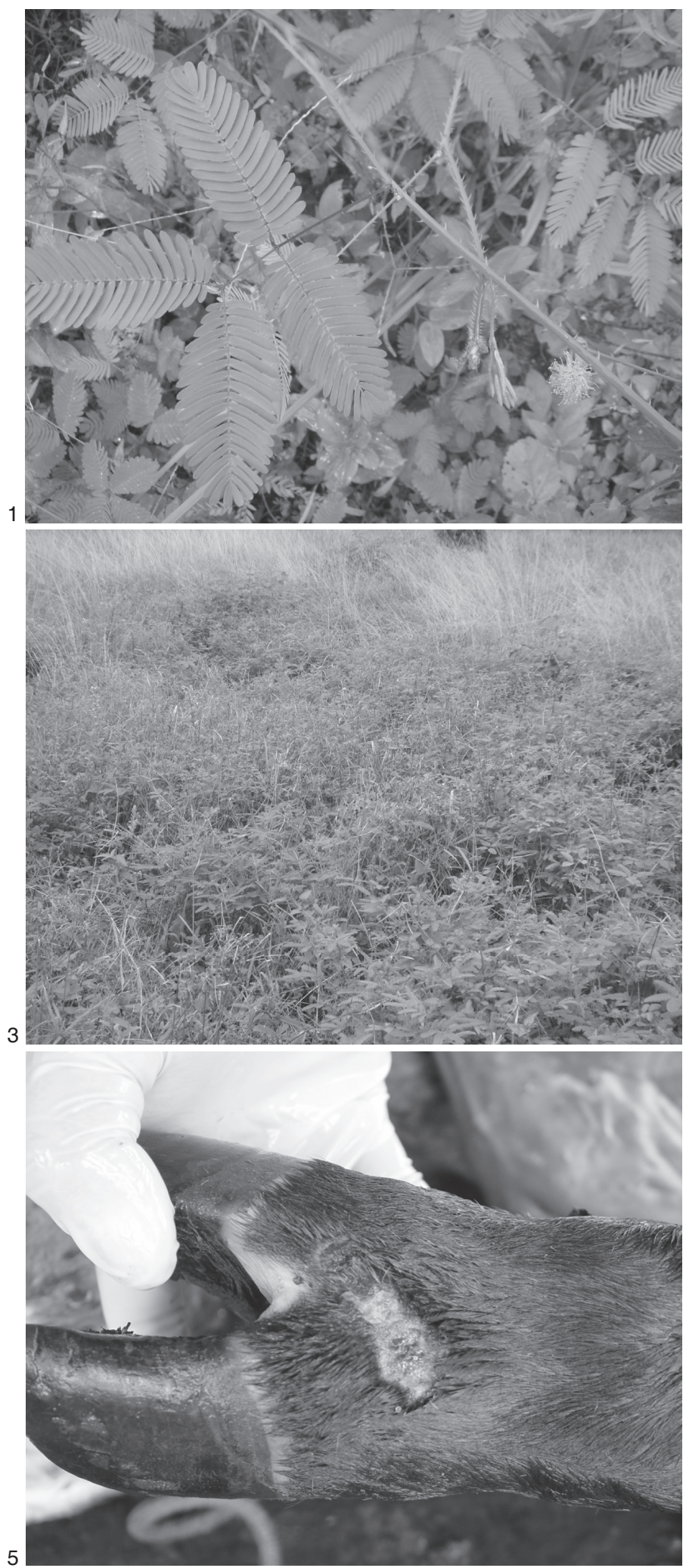

Fig.1. Aspecto das folhas de Mimosa pudica (Leg. Mimosoideae). Castanhal, PA.

Fig.3 e 4. Pastagem fortemente infesta por Mimosa pudica. Castanhal, PA.
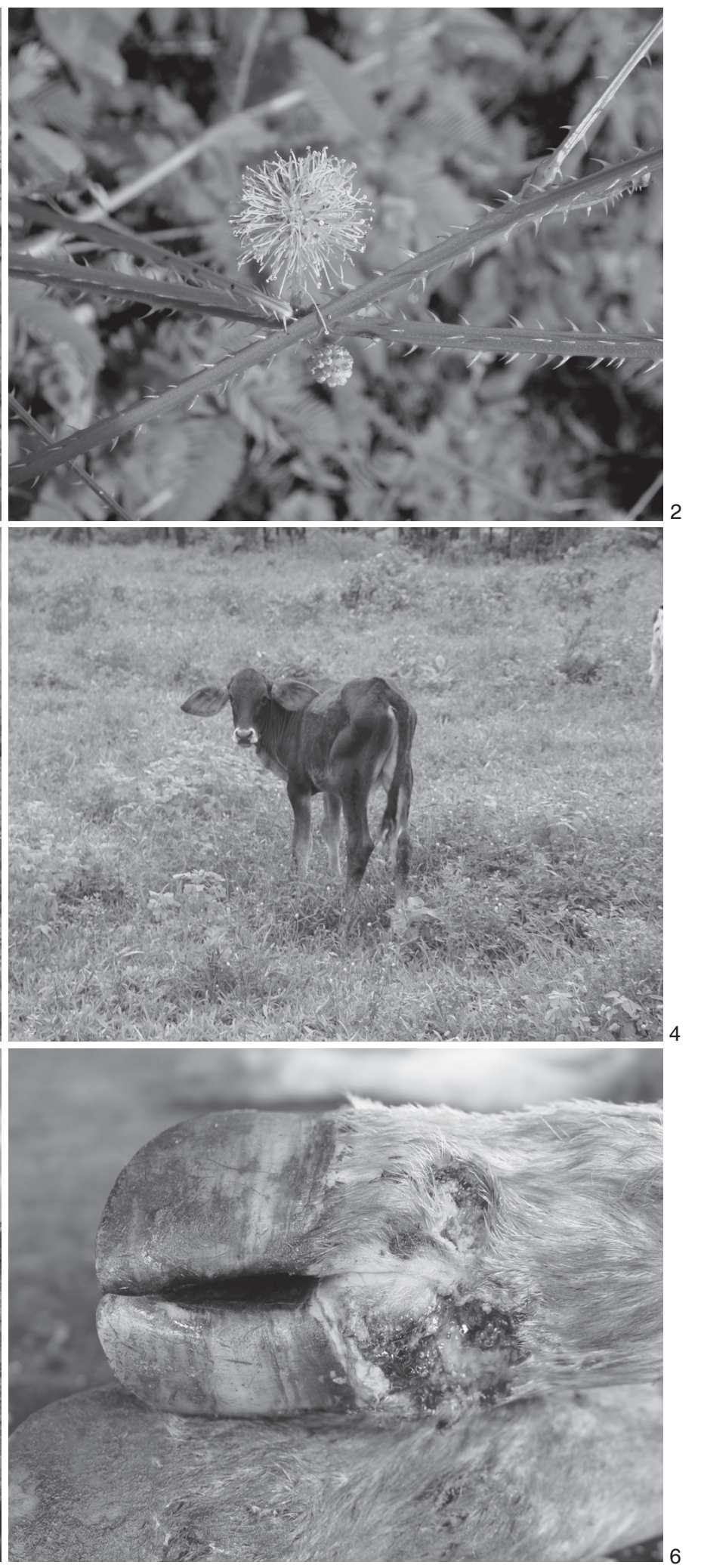

Fig.2. Aspecto do caule provido de espinhos de Mimosa pudica e inflorescência. Castanhal, PA.

Fig.5, 6. Feridas na superfície dorsal das quartelas de bezerros, causadas pelos espinhos de Mimosa pudica. Castanhal, PA. 

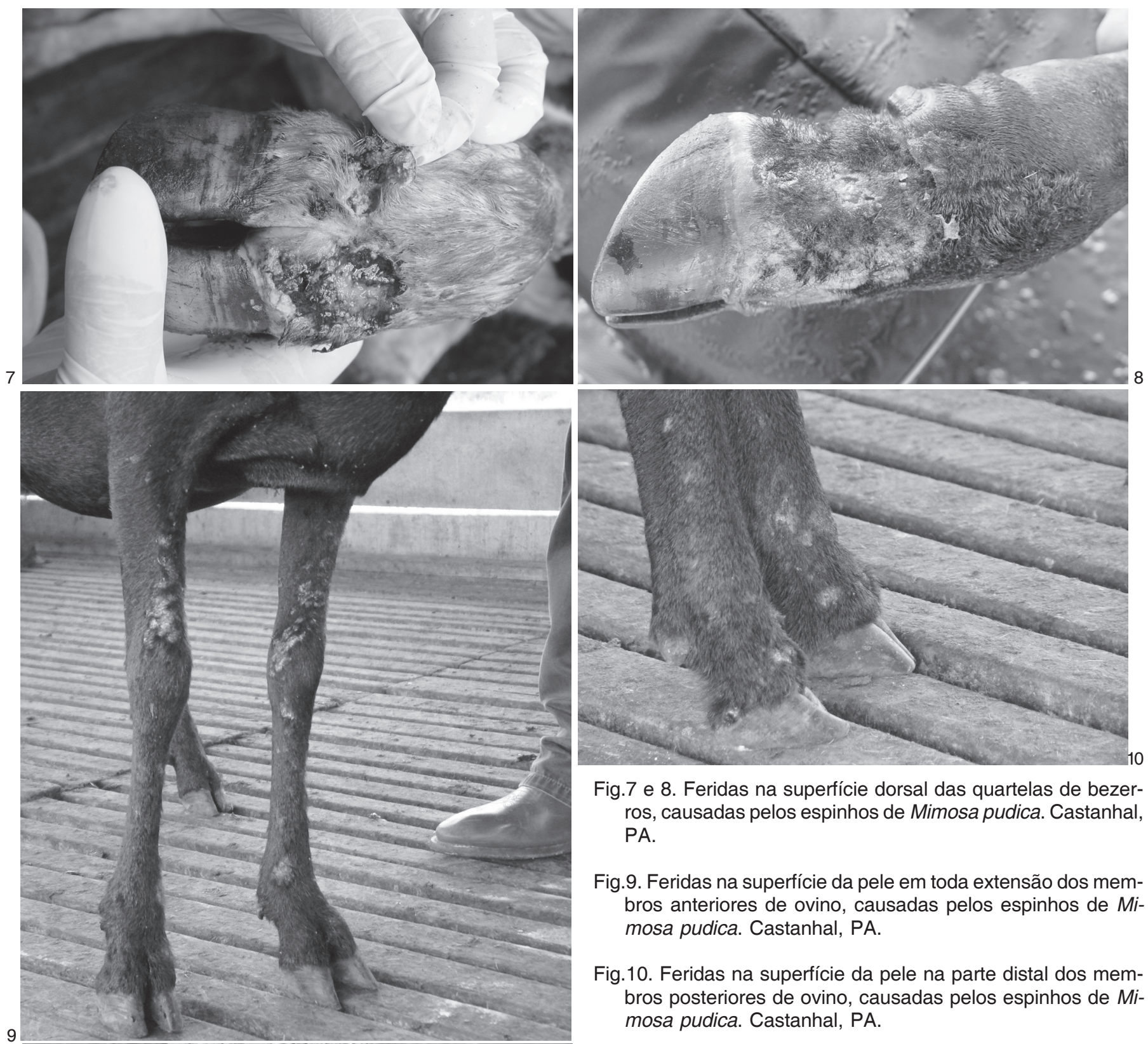

Fig.7 e 8. Feridas na superfície dorsal das quartelas de bezerros, causadas pelos espinhos de Mimosa pudica. Castanhal, PA.

Fig.9. Feridas na superfície da pele em toda extensão dos membros anteriores de ovino, causadas pelos espinhos de $\mathrm{Mi}$ mosa pudica. Castanhal, PA.

Fig.10. Feridas na superfície da pele na parte distal dos membros posteriores de ovino, causadas pelos espinhos de $\mathrm{Mi}$ mosa pudica. Castanhal, PA.

Fig.11. Proliferação de fibroblastos (tecido de granulação) no derma. HE, obj.10x.

\section{RESULTADOS}

Segundo informações obtidas, os bovinos e ovinos apresentavam as lesões poucos dias após serem colocados em certos pastos e recuperavam-se rapidamente quando retirados dos mesmos. À inspeção dos pastos constatouse grande quantidade de "malícia", planta cujos caules são providos de espinhos; a planta foi identificada como Mimosa pudica, da família Leguminosa Mimosaceae (Fig.1-4). Oito dos 40 bezerros (15\%) e 12 dos 50 ovinos $(22 \%)$, examinados nas duas propriedades apresentavam lesões na pele dos membros. Nos bovinos as lesões eram localizadas nos espaços interdigitais e, principalmente, 
nas superfícies dorsais dos boletos e quartelas (Fig.5-10). Essas se caracterizavam por ulcerações da pele, com contornos irregulares e exsudação sanguinolenta, em alguns casos recobertos por crostas. Nos ovinos, as lesões eram semelhantes às dos bovinos, porém presentes desde as articulações escápulo-umeral e do jarrete até a extremidade dos membros. Os achados histopatológicos revelaram uma reação inflamatória, caracterizada pela presença de derrame fibrinoso no derma com forte extensa reação fibroblástica (tecido de granulação) e de epidermite supurativa aguda com presença de colônias bacterianas e de eosinófilos (Fig.11).

\section{DISCUSSÃO E CONCLUSÕES}

Baseado no conjunto dos dados, isto é, na presença de grande quantidade de Mimosa pudica nos pastos onde incidia a doença, na recuperação dos animais depois de retirada destes pastos, nas características da planta com espinhos no caule, nas lesões ulcerativas na pele dos membros e nos achados histopatológicos, concluimos que a doença é causada pela ação traumática de Mimosa pudica.

Na África e na América do Sul já foram descritas várias plantas que possuem espinhos ou frutos os quais causam traumatismo na pele e em outras partes do corpo de bovinos e ovinos, com danos consideráveis à saúde, inclusive morte (Kellerman et al. 2005). Não encontramos na literatura brasileira, dados sobre plantas que provocam esse tipo de lesão nos animais domésticos. O comprometimento de uma maior região do corpo dos ovinos, pelas lesões, pode ser explicado pelo menor porte dos animais

No entanto, é necessário o diagnóstico diferencial com algumas enfermidades que causam lesões de pele dos membros, como ergotismo, salmonelose e fotossensibilização hepatógena.
O ergotismo também causa lesões cutâneas nas extremidades dos membros, porém nessa enfermidade sob forma de gangrena pela vasoconstrição. Na salmonelose também pode ocorrer gangrena seca das extremidades, em decorrência de vasculite. As lesões observadas nos bovinos e ovinos do presente estudo são de natureza traumática (Radostits et al. 2000, Barros 2007, Riet-Correa \& Méndez 2007).

$\mathrm{Na}$ fotossensibilização hepatógena os animais apresentam lesões com desprendimento da pele, também em outras regiões do corpo, preferencialmente despigmentadas (Schild 2007).

Agradecimentos.- Ao Prof. Pedro Germano Filho, Instituto de Biologia da Universidade Federal do Rio de Janeiro (UFRRJ), pela identificação do material botânico, e ao Setor de Anatomia Patológica do Convênio "Projeto Sanidade Animal Embrapa/UFRRJ" pelos exames histopatológicos.

\section{REFERÊNCIAS}

Barros C.S.L. 2007. Salmonelose, p.416-425. In: Riet-Correa F., Schild A.L., Lemos R.A.A. \& Borges J.R.J. (Eds), Doenças de Ruminantes e Eqüídeos. Vol.1. $3^{\underline{a}}$ ed. Pallotti, Santa Maria, RS. 722p.

Kellerman T.S., Coetzer J.A.W., Naudé T.W. \& Botha C.J. 2005. Plant Poisonings and Mycotoxicoses of Livestock in Southern Africa. $2^{\text {nd }}$ ed. Oxford University Press, Cape Town. 310p.

Radostits O.M., Gay C.C., Blood D.C. \& Hinchcliff K.W. 2000. Clínica Veterinária: Um tratado de doenças dos bovinos, ovinos, suínos, caprinos e eqüinos. $9^{\mathrm{a}}$ ed. Guanabara Koogan, Rio de janeiro. 1737p.

Riet-Correa F. \& Méndez M.D.C. 2007. Ergotismo por Claviceps purpurea, p.213-217. In: Riet-Correa F., Schild A.L., Lemos R.A.A. \& Borges J.R.J. (Eds), Doenças de Ruminantes e Eqüídeos. $3^{\text {a }}$ ed. Vol.2. Pallotti, Santa Maria, RS. 694p.

Schild A.L. 2007. Fotossensibilização hepatógena, p.39-42. In: RietCorrea F., Schild A.L., Lemos R.A.A. \& Borges J.R.J. (Eds), Doenças de Ruminantes e Eqüídeos. Vol.2. 3aㅡ ed. Pallotti, Santa Maria, RS. $694 p$. 